\title{
Idiopathic Gingival Enlargement: A case report
}

\author{
Rajesh Shah ${ }^{1}$, Shivalal Sharma ${ }^{2}$ \\ ${ }^{1}$ MDS (Periodontology and Oral Implantology) ${ }^{2}$ Professor \& HOD, Dept. of Periodontology and Oral \\ Implantology, CODS, BPKIHS
}

Correspondence
Dr Rajesh Shah
College of Dental Surgery, BPKIHS
E mail: coldstar190@gmail.com
DOI: http://dx.doi.org/10.3126/
jcmsn.v11i1.13319

\begin{abstract}
Idiopathic gingival fibromatosis is a relatively rare condition characterized by the proliferation of the gingival tissues resulting in masticatory, esthetics, phonetics and psychological disturbances. We present a case with generalized diffuse gingival enlargement involving the maxillary and mandibular arches extending on buccal and lingual/ palatal surfaces and covering incisal/occlusal third of the tooth in the left maxillary region. Gingivectomy was carried out in all four quadrants. Periodic recalls showed maintenance of good oral hygiene and one year follow-up revealed no recurrence.

Key words: Gingival enlargement, gingivectomy, idiopathic gingival fibromatosis
\end{abstract}

Citation: Shah R, Sharma S. Idiopathic Gingival Enlargement: A case report. JCMS Nepal 2015;11 (1):26-28.

\section{INTRODUCTION}

Idiopathic gingival fibromatosis (IGF) is a rare hereditary condition with no definite cause. ${ }^{1}$ The overgrowth varies from mild enlargement of an isolated inter dental papillae to segmental or uniform and marked enlargement affecting one or both the jaws. ${ }^{2}$

The etiopathogenesis of gingival enlargement (GE) is poorly understood but can be directly or indirectly attributed to factors like plaque accumulation; inadequate nutrition or systemic hormonal stimulation. ${ }^{3} \mathrm{GE}$ is also evidenced in blood dyscrasias or may result from factors like inflammation, drugs and inheritance. ${ }^{4}$

Due to massive gingival enlargement, an affected child usually develops an abnormal swallowing pattern and experiences difficulty in speech and mastication. Along with these features, there may be some interference with maintenance of oral hygiene and mastication. All these factors will favor accumulation of material alba and plaque, which further complicates the existing hyperplastic tissue. $^{5}$

\section{CASE REPORT}

A 26-year-old female reported to the Department of Periodontology \& Oral Implantology with a chief complaint of swollen gums involving all her teeth since 13 years which interfered with proper speech, and mastication, causing inadequate lip apposition and poor esthetics.

She did not give any history of drug intake, fever, anorexia, weight loss, seizures, hearing loss, nor having any physical or mental disorder. Also familial and postnatal history were non-contributory Extra-oral examination revealed incompetent everted lips and a convex profile. The teeth were barely visible as the enlarged gingiva covered teeth completely in maxillary left region.

Open bite was present. An intraoral examination revealed generalized, diffused, nodular enlargement of the gingiva involving the upper and lower arches, which were pink in color, and had a firm and fibrous consistency.

\section{INVESTIGATIONS:}

Intraoral bitewing and panoramic radiographs revealed no bone loss.(Fig.2) Over-retained deciduous teeth (64 and 65) were present. Hematological investigations were within normal limits. Occipitomental view-was taken to detect radiographic anatomy of facial bones and mandible.

\section{TREATMENT:}

After completion of Phase I therapy, a quadrantwise gingivectomy was performed under local anesthesia (Fig .3a.,3b.,3d.,3e.) Coe-pack was given in all four quadrants to reduce patient discomfort. Patient was recalled after one week to remove periodontal dressing in each appointment. Analgesic and antiseptic mouthwash were prescribed as required.

Biopsy was carried out and histopathological examination revealed acutely inflamed and congested stratified squamous lining epithelium. 
Subepithelial interphase showed moderately dense inflammation by chronic inflammatory cells comprising of lymphocytes and plasma cells with subjacent fibrosis.(Fig.4)
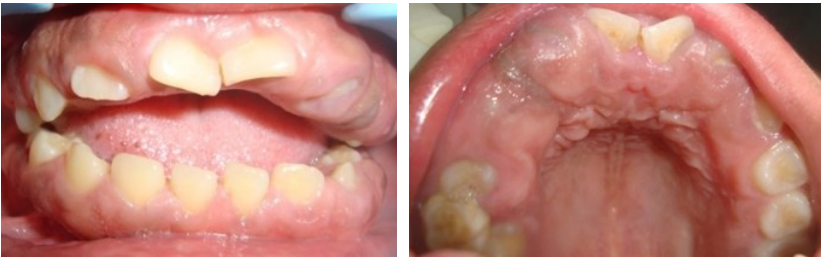

Fig 1a. Pre-operative anterior view

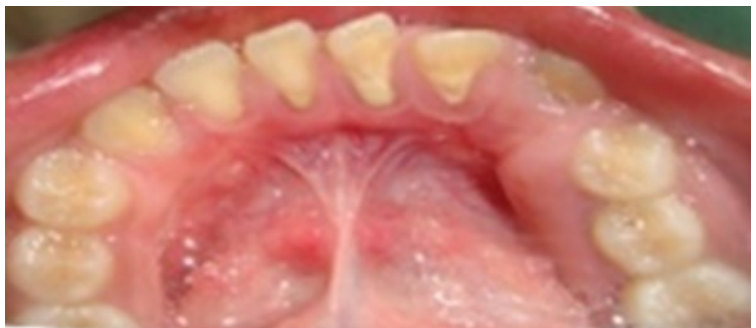

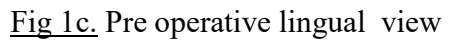

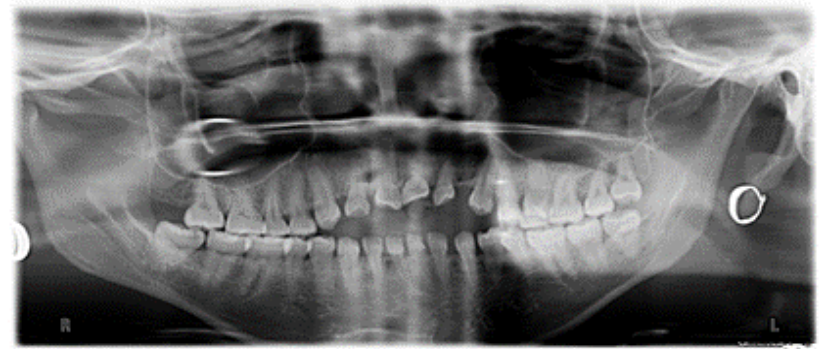

Fig 2. Pre operative Orthopantomogram

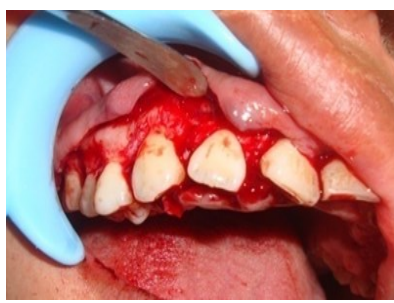

Fig 3a. Intraoperative right maxillary buccal view Gingivectomy done

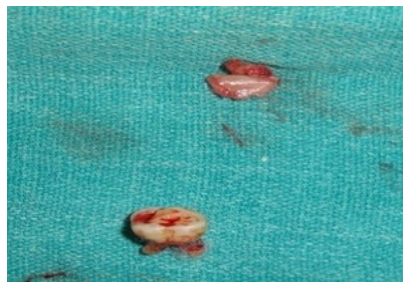

Fig 3c. Extraction of retained decidious teeth

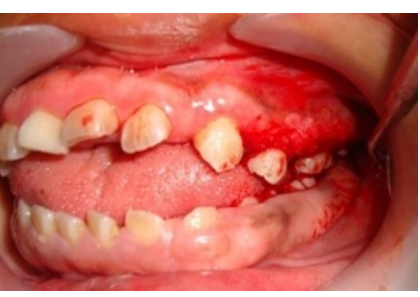

Fig 3b. Intraoperative Left maxillary buccal view Gingivectomy done

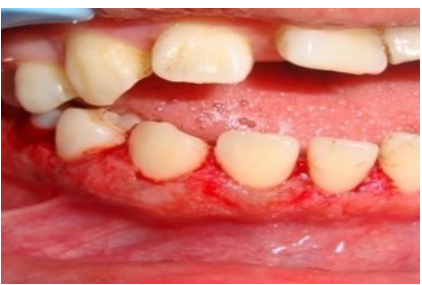

Fig 3d. Mandibular Right quadrant: Intraoperative buccal view Gingivectomy done

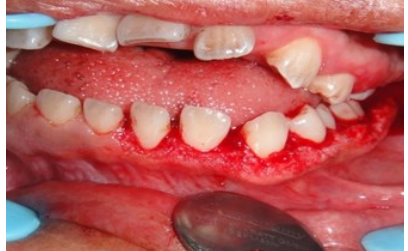

Fig 3e. Mandibular left quadrant: Intraoperative buccal view Gingivectomy done

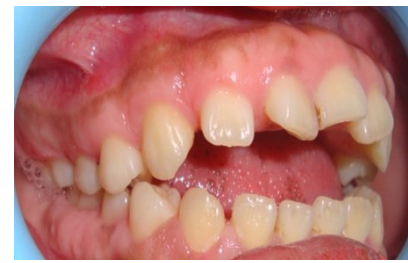

Fig5a. Postoperative Max. and Mand. Right quadrant after 8 months

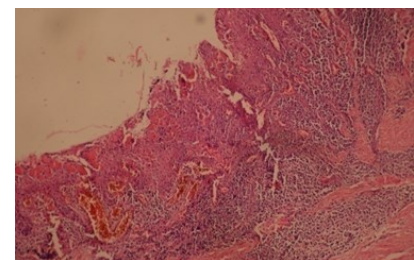

Fig4. Histopathological view. (biopsy done before surgery)

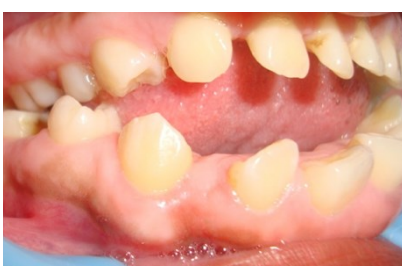

Fig 5b. Postoperative max. and Mand. Left quadrant after 8 months

\section{DISCUSSION}

IGF may be congenital or hereditary. Though the genetic mechanism is not well understood, the majority of the reported cases have attributed the condition of fibrous enlargement of gingiva to hereditary factors. The mode of transmission is mainly autosomal dominant. The first polymorphic marker for HGF phenotype is chromosome $2 \mathrm{p} 21 i^{6,7}$ Many cases are sporadic with no familial background. Gingival hyperplasia may be associated with physical development, retardation, and hypertrichosis. ${ }^{8}$

Although gingival tissue may appear normal at birth, hyperplastic GF may become evident with the eruption of primary or permanent dentition, suggesting a trauma-induced tissue reaction during

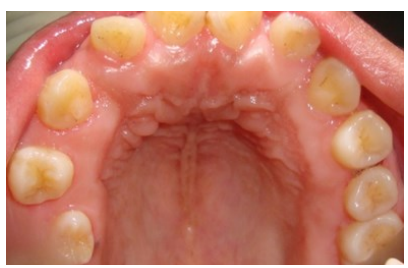

Fig 5c. Post operative palatal view after 8 months

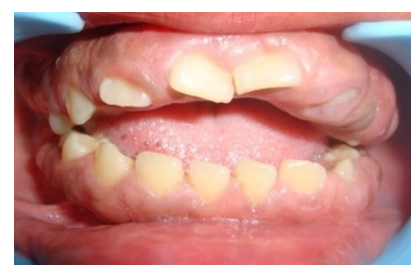

Fig 6. Preoperative view

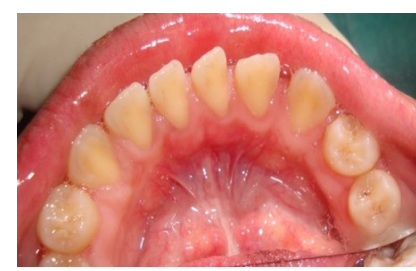

Fig 5d. Post operative lingual View after 8 months

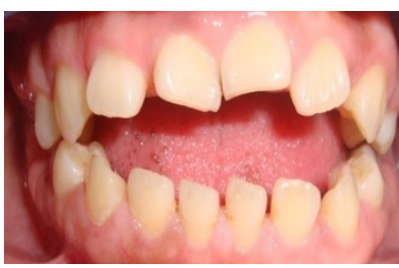

Fig 7. Post operative Anterior view after 8 month 
the eruption. ${ }^{9}$ Sometimes gingival enlargement does not occur until the eruption of the permanent dentition. Further enlargement does not occur once the growth of jaw is completed. ${ }^{10}$ It has been suggested that gingival enlargement may be due to nutritional and hormonal factors; however, these have not been completely substantiated. Histologically, IGE shows a bulbous increase in the amount of connective tissue that is relatively avascular and consists of densely arranged collagen bundles and numerous fibroblasts. The surface epithelium is thickened and acanthotic with elongated rete pegs. Due to massive gingival enlargement, an affected child usually develops abnormal swallowing pattern and experiences difficulty in speech and mastication. Along with these features, there may be some interference with the oral hygiene measures and normal mastication. Gingival hyperplasia can occur after therapy with drugs like phenytoin, cyclosporine, nifedipine, and nitrendipine. ${ }^{11}$

Long term use of these drugs has to be ruled out. The incidence of gingival enlargement caused by phenytoin, an anticonvulsant used in the treatment of epilepsy varies from 3-84.5\%.Various treatment modalities for the management of IGF include external or internal bevel gingivectomy in association with gingivoplasty, an apically positioned flap, electrocautery and the use of lasers.

The most effective method for removing the enlarged tissue when there is no attachment loss and all the pocketing is false, is the conventional external bevel gingivectomy. ${ }^{12}$

Since recurrence could be expected within a few months after surgery and may return to the original condition within few years, the patient may have to undergo repeated gingivectomy procedures. This often causes further increase in the patients' and parents' psychological and emotional stress. Hence, psychological counseling is a must for patients and parents.

\section{CONCLUSION}

IGF is a relatively rare condition with poorly understood etiopathogenesis and recurrence rates. The benefits of the surgery outweigh the risks of recurrence and should be employed whenever deemed crucial. Patient education, periodic recall and proper oral hygiene maintenance reduce and delay the chances of recurrence. Further studies at cellular, molecular and genetic levels are required to understand the etiology and pathogenesis of this bizarre condition.

Even though recurrence cannot be predicted, the psychological and functional benefits far outweigh the risk of recurrence. Oral hygiene and the superimposition of plaque accumulation have a crucial effect on the prognosis. Long-term followup will be required to evaluate.

\section{REFERENCES}

1. Carranza FA, Hogan EL. Gingival enlargement. In: Newman MG, Takei HH, Carranza FA, editors. Clinical Periodontology. 9th ed. Philadelphia, PA, USA: Saunders; 2002. p. 279-96.

2. Tiwana PS, De Kok IJ, Stoker DS, Cooper LF. Facial distortion secondary to idiopathic gingival hyperplasia: Surgical management and oral reconstruction with endosseous implants. Oral Surg Oral Med Oral Pathol Oral RadiolEndod 2005;100:153-7. DOI: http://dx.doi.org/10.1016/j.tripleo.2003.12.024

3. Regezi JA, Sciuba JJ. Connective tissue lesions. In: Oral Pathology: Clinical pathologic Correlations. Philadelphia, PA, USA: W.B. Saunders; 1999. p. 179-83.

4. DongariBagtzoglou A, Research, Science and Therapy Committee American Academy of Periodontology. Drug associated gingival enlargement. J Periodontol 2004;75:1424-31.

DOI: http://dx.doi.org/10.1902/jop.2004.75.10.1424

5. Ramer M, Marrone J, Stahl B, Burakoff R. Hereditary gingival fibromatosis: Identification, treatment, control. J Am Dent Assoc 1996;127:493-5. DOI: http://dx.doi.org/10.14219/jada.archive.1996.0242

6. Cortelli JR. Evidence of genetic heterogenecity for hereditary gingival fibromatosis. J Dent Res 2000;79:1758 $-64$.

DOI: http://dx.doi.org/10.1177/00220345000790100501

7. Hart TC, Pallos D, Bowden DW, Bolyard J, Pettenati MJ, Cortelli JR. Linkage of hereditary gingival fibromatosis to chromosome 2 21. Am J Hum Genet 1998;62:876-83. DOI: http://dx.doi.org/10.1086/301797

8. Shafer WG, Hine MK, Levy BM. Developmental disturbances of the perioral structures. 4th ed. (Philadelphia) A Prisma Indian; 1993. p. 23-4.

9. Gupta N, Maheshwari S. Advanced gingival fibromatosis. J Indian Dent Assoc 1996;167:46-7.

10. Stewart RE. Periodontal diseases in children. Pediatric Dentistry and Clinical Practice. USA: Mosby Company; 1982.

11. Angelopoulos AP, Goaz PW. Incidence of diphenylhydantoin gingival hyperplasia. Oral Surg Oral Med Oral Pathol 1972;34:898-906. DOI: http://dx.doi.org/10.1016/0030-4220(72)90228-9

12. Devi PK, Kumar GP,Bai YD, Ammaji AD. Ipsilateral idiopathic gingival enlargement and its management using conventional gingivectomy and diode laser: A recurrent case after 15 years, J Indian SocPeriodontol2013 MayJun;17(3):387-90. DOI: http://dx.doi.org/10.4103/0972124X.115649 